\title{
Spectrum of ATP7B Gene Mutations in Pakistani Wilson Disease Patients: A Novel Mutation Is Associated with Severe Hepatic and Neurological Complication
}

\author{
Abdul Khaliq Naveed (Corresponding Author) \\ Dept. of Biochemistry and Molecular Biology, Army Medical College \\ National University of Sciences and Technology, Rawalpindi, Pakistan \\ Tel: 92-51-5613-2787_E-mail: khaliqnaveed2001@yahoo.com \\ Asifa Majeed \\ Dept. of Biochemistry and Molecular Biology, Army Medical College \\ National University of Sciences and Technology, Rawalpindi, Pakistan \\ Tel: 92-51-5613-2787 E-mail: majeed_8@hotmail.com \\ Sumreena Mansoor \\ Dept. of Biochemistry and Molecular Biology, Army Medical College \\ National University of Sciences and Technology, Rawalpindi Pakistan \\ Tel: 92-51-5613-2787 E-mail: dr.sumreena@yahoo.com
}

\begin{abstract}
Wilson disease (WND) is an autosomal recessive disorder caused by mutation in ATP7B gene that impairs copper metabolism. ATP7B is involved in the transport of copper into the plasma protein ceruloplasmin and copper excretion out of the liver. Defects in ATP7B lead to excess of copper in various organs primarily in liver. The diagnosis of WND is more complex due to variations in its biochemical and clinical features and the broad range of disease onset. The objective of the present study was to establish molecular analysis system for screening of Wilson disease in Pakistani population. Three mutations were identified; with one being is a novel mutation never reported before.
\end{abstract}

Keywords: ATP7B, Neurological Disorder, Ceruloplasmin, Wilson Disease, Pakistani population

\section{Introduction}

Wilson disease (WND) is an autosomal recessive disorder of copper metabolism described by Wilson in 1912. Patients with WND usually suffer from hepatic, neurologic and psychiatric complications. Most frequently findings associated with WND are low serum ceruloplasmin level, high concentrations of copper in liver and the presence of Kayser-Fleischer (KF) ring (Sternlieb, 1980, 1990). The worldwide prevalence of WND was reported to be 1 in 30,000 with a carrier ratio of 1 in 90 (Scheinberg and Sternlieb, 1984). The symptoms appear between ages 5 to 35 (Schoen and Sternlieb, 1990) but it can vary from 2-years old to 72 years (Ala et al., 2005; Beyersdorff et al., 2006; Wilson et al., 2000). It is generally believed that WND is caused by defect in ATP7B gene located on q14.3 band of chromosome 13 which was cloned in 1993 (Bull et al., 1993; Yamaguchi et al., 1993; Tanzi et al., 1993). ATP7B gene consists of six copper binding domains, eight transmembrane domains and ATP loop that transports copper into bile. ATP7B is a copper-transporting P-type ATPase involved in transporting copper into the secretory pathway for incorporation into apoceruloplasmin and excretion of copper into the bile (Bartee et al., 2007; Ferenci, 2004; Hellman et al., 2002). Mutation in ATP7B gene can impair the protein function leading to accumulation of copper in liver, kidney and cornea. The diagnosis of WND is much complex due to variations in biochemical and clinical features and broad range of disease onset. Therefore, molecular diagnosis plays a pivotal role in pre-symptomatic diagnosis of WND and effected individuals can get treatment in time to prevent further progression of disease. 
This study was performed to screen patients with WND through molecular genetic testing for ATP7B gene mutation and establish a molecular diagnostic system for detection of pre-symptomatic WND. This may serve as a very useful approach for early introduction of therapeutic intervention in order to check the progression of the disease.

\section{Materials and Methods}

This study was approved by the ethical committee of National University of Sciences and Technology. Informed consent was obtained from 11 WND patients included in this study. There were (5) males and (6) females with the mean age 6.3. \pm 1.35 (hepatic manifestation), $15 \pm 5.6$ (hepatic \& neurological complications) and 19-yeras (neurological manifestation). Each of these patients had a score of at least 3 according to a scoring system based on clinical and biochemical parameters. The patients were diagnosed on the basis of clinical features such as presence of hepatic disturbance, typical neurological symptoms, low serum ceruloplasmin concentration, high urinary copper level and presence of the KF ring. The molecular genetic analyses were also performed for detection of mutation in the ATP7B gene. The WND patients and their family members were screened through molecular genetic testing. The healthy individuals were included as control for the confirmation of mutation. Genomic DNA was extracted from peripheral blood of patients as well their family members and healthy individuals by standard phenol/chloroform extraction method. The exons 2, 3, 8, 13, 14 of ATP7B gene were used for PCR and direct sequencing (forward and reverse strands) on CEQ8000 Genetic Analyzer (Beckman Coulter). The mutations in WND patients were confirmed in repeated experiments and through comparison with their parents and controls.

\section{Results}

A total of 11 WND patients were clinically examined. All patients had shown variations in clinical features and biochemical analysis. Eight patients had a hepatic manifestation confirmed through ultrasonoghraphy and liver biopsy, 1 showed severe neurological symptom and 2 had both neurological and hepatic complications (Table $1 \& 2$ ). All patients were receiving chelation and oral zinc treatment. The mutation analysis had confirmed the defect in entire ATP7B gene in three patients. Three variants were identified at exon $2 \& 3$ with one novel never reported before. The insertion (c.815-816insT) at exon 2 was resulted in premature protein truncation with creation of stop codon 10bp downstream (Figure-1d). This novel frameshift mutation might have produced functionless protein. This patient-1 was presented with severe hepatic \& neurological complications of WND. The patient was died within six month after disease onset. Her sister was earlier died of WND. The patient's parents were found normal in both biochemical and genetic analysis. The sibling was found negative in KF ring and urinary copper analysis but ceruloplasmin level was at border range and under investigation through mutation analysis. This case shows the importance of molecular genetic testing for diagnosis of Wilson disease.

The non-sense mutation Cys271X (Figure-1e) in exon 2 was previously reported (Hao et al., 1998, Gupta et al., 2005). The patient having this non-sense mutation had severe neurological symptoms like dystonia, dysarthria and arthralgia. Behavioral and psychiatric changes were also developed in later stage of treatment. This nonsense mutation was resulted in the premature truncation of protein at amino acid residue 271. The c.G1366C (Figure-1f) resulted in valine transition to leucine on exon 3 was detected as nonpathogenic variation as described previously (Gupta et al., 2007).

\section{Discussion}

Early diagnosis of WND disease is very crucial to prevent its progression. Late onset of Wilson disease is also creating hinders in proper diagnose and treatment. We have identified several cases where late onset of disease caused a sudden death of patient (personal communication). Investigation of genotype-phenotype correlations in WND is impeding by a variety of factors. The frequency of most mutations is low and initial symptoms of WND may be nonspecific and will not be easily recognized, resulting in a considerable diagnostic delay and imprecise clinical data (Caca et al., 2001). Therefore molecular genetic testing is a powerful tool for pre-symptomatic diagnose and proper treatment of this disease. Our clinical data has confirmed these findings. In our study, two patients were presented with severe hepatic symptoms but KF ring was absent. Similarly, one patient had neurological type of Wilson disease but developed KF ring at the age of 20 years.

The two frameshift mutations have resulted in premature protein truncation and expected as disease causing mutations. The fulminant hepatic failure and early symptoms in WND are related to nonsense or frameshift mutations that encode a truncated ATP7B protein having significant functional loss and being responsible for the seriousness of the disease (Okada et al., 2000). There are several factors involved in the pathogenesis of WND (Schilsky, 2005). Both insertion and non-sense mutations found here were diseases causing affected copper domain 3. The insertion of $\mathrm{T}$ at nucleotide position 816 although does not change the amino acid, but resulted in premature termination.

All patients examined in this study had strong hepatic and neurological symptoms as compare to control. We have concentrated specifically on exon 8 \& 14. The occurrence of most common mutation H1069Q (Olivarez et al., 2001) and R778L (Mak et al., 2008) are reported on these exons. The frequencies of R778L mutation have been reported $14.6 \%$ in Japanese patients (Nanji et al., 1997), 37.5\% in Korean patients (Kim et al., 2000), 30\% Chinese patients (Fan 
et al., 2002). Both mutations were not detected in our patients. The onset of WND in neurological and hepatic patient was same as reported earlier that hepatic disorders are major symptoms during childhood and neuropathy becomes evident during adolescence (Shimizu and Nakazono, 1999; Ferenci, 2001; Roberts and Schilsky, 2003).

Our report is the first local study to elucidate the genotype of ATP7B gene in Pakistani WND patients. The detection of either novel or common mutations will help to assess their impact on disease severity and functional characterization will open the way to understand the mechanisms of protein dysfunction for particular mutation of ATP7B. This study will help in screening heterozygote carrier to prevent progression of disease in a family or population.

\section{Acknowledgments}

We are thankful to NCVI of National University of Sciences and Technology for providing sequencing reagents. We are also thankful to Ms. Shazia, Mr. Fareed and Mr. Zia for providing technical assistance.

\section{References}

Ala, A., Borjigin, J., Rochwarger, A., \& Schilsky, M. (2005). Wilson disease in septuagenarian siblings: raising the bar for diagnosis. Hepatology, 41, 668-670.

Bartee, M.Y., \& Lutsenko, S. (2007). Hepatic copper-transporting ATPase ATP7B: function and inactivation at the molecular and cellular level. Biometal, 20, 627-637.

Beyersdorff, A., Findeisen, A., \& Morbus, A. (2006). Wilson: case report of a two year-old child as first manifestation. Scandnavian Journal of Gastroenterology, 41, 496-7.

Bull, P.C., Thomas, G.R., Rommens, J.M., Frobes, J.R., \& Cox, D.W. (1993). The Wilson disease gene is a putative copper transporting p-type ATPase similar to the Menkes gene. Nature Genetics, 5, 327-337.

Caca, K., Ferenci, P., Kuhn, Hans-Jurgen., Polli, C., Willgerod, H., Kunath, B., Hermann, W., Mossner, J., \& Berr, F. (2001). High prevalence of the H1069Q mutation in East German patients with Wilson disease: rapid detection of mutations by limited sequencing and phenotype-genotype analysis. Journal of Hepatology, 35, 575-581.

Chuang, L.M., Wu, H.P., \& Jang, M.H. (1996). High frequency of two mutations in codon 778 in exon 8 of the ATP7B Gene in Taiwanese with Wilson Disease. Journal of Medical Genetic, 33, 521-523.

Fan, Y., Yu, L., Jiang, Y., Xu, Y., Yang, R., \& Han, Y. (2002). Identification of a mutation hotspot in exon 8 of Wilson disease gene by cycle sequencing. Chinese Medical Journal, 113, 172-174.

Ferenci, P. (2001). Wilson disease. Indian Journal of Gastroenterology, 20, C71-C78.

Ferenci, P. (2004). Review article: diagnosis and current therapy of Wilson's disease. Aliment Pharmacology Theory, 19, 157-165.

Gupta, A., Aikath, D., Neogi, R., Datta, S., Basu, K., Maity, B., Trivedi, R., Ray, J., Das, S.K., Gangopadhyay, P.K., \& Ray, K. (2005). Molecular pathogenesis of Wilson disease: haplotype analysis, detection of prevalent mutations and genotype-phenotype correlation in Indian patients. Human Genetics, 118, 49-57.

Gupta, A., Chattopadhyay, I., Dey, S., Nasipuri, P., Das, S.K., Gangopadhyay, P.K., \& Ray, K. (2007). Molecular pathogenesis of Wilson disease among Indians: a perspective on mutation spectrum in ATP7B gene, prevalent defects, clinical heterogeneity and implication towards diagnosis. Cell Molecular Neurobiolology, 27, $1023-1033$.

Ha-Hao, D., Hefter, H., Stremmel, W., Castaneda-Guillot, C., Hernandez, H.A., Cox, D.W., and Auburger, G. (1998). His1069Gln and six novel Wilson disease mutations: analysis of prevelance for early diagnosis and. European Journal of Human Genetics, 6, 616-623.

Hellman, N.E., Kono, S., Mancini, G.M., Hoogeboom, A.J., DeJong, G.J., \& Gitlin, J.D. (2002). Mechanisms of copper incorporation into human ceruloplasmin. Journal of Biology \& Chemistry, 277, 46632-8.

Kim, E.K., Yoo, O.J., Song, K.Y., \& Yoo, H.W., Choi, S.Y., Cho, S.W \& Hahn, S.H. (1998). Identification of three novel mutations and a high frequency of the Arg778leu mutation in Korean patients with Wilson disease. Human Mutation, 11, 275-278.

Mak, C.M., Lam, C.V., Tam, S., Lai, C.L., Yuen, L., Tat, C.S., Yu-Lung, F., Jak-Yiu, L., \& Lai, L.P. (2008). Mutational analysis of 65 Wilson disease patients in Hong Kong Chinese: Identification of 17 novel mutations and its genetic heterogeneity. Journal of Human Genetics, 53(4), 55-63.

Nanji, M.S., Nguyen, V.T., Kawasoe, J.H., \& Endo, F. (1997). Haplotype and mutation analysis in Japanese patients with Wilson disease. American Journal of Human Genetics, 60, 1423-1429.

Okada, T., Morise, T., Takeda, Y. \& Mabuchi, H. (2000). A new variant deletion of a copper-transporting P-type ATPase gene found in patients with Wilson's disease presenting with fulminant hepatic failure. Journal of Gastroenterology, 35, 278-83. 
Olivarez, L., Caggana, M., Pass, K.A., Ferguson, P., \& Brewer, G.J. (2001). Estimate of the frequency of Wilson's disease in the US Caucasian population: a mutation analysis approach. Annals of Human Genetic, 65, 459-463.

Roberts, E.A., \& Schilsky. M.L. (2003). A practical guideline on Wilson disease. Hepatology, 37, 475-1492.

Scheinberg, I. \& Sternlieb, I. (1984). Wilson disease. In, H. Lloyd., \&, J. Smith (Eds), Major problems in internal medicine. Philadelphia: Saunders. pp-23.

Schilsky, M.L. (2005). Wilson disease: New insights into pathogenesis, diagnosis, and future therapy. Current Gastroenterology Report, 7, 26-31.

Schoen, R.E., \& Sternlieb, I. (1990). Clinical aspects of Wilson's disease. American Journal of Gastroenterology, 85, 1453-7.

Shimizu, N., \& Nakazono, H. (1999). Molecular analysis and diagnosis in Japanese patients with Wilson's disease. Pediatrics International, 41, 409-413.

Sternlieb, I. (1980). Copper and the liver. Gastroenterology, 78, 1615-28.

Sternlieb, I. (1990). Perspectives on Wilson's disease. Hepatology, 12, 1234-9.

Tanzi, R.E., Petrrukhin, K., Chernov, I., Pellequer, J.L., Wasco, W., \& Ross, B. (1993). The Wilson disease gene is a copper transporting ATPase with homology to Menkes disease gene. Nature Genetics, 5, 344-350.

Wilson, D.C., Phillips, M.J., Cox, D.W., \& Roberts, E.A. (2000). Severe hepatic Wilson's disease in preschool-aged children. Journal of Pediatrics, 137, 719-722.

Wilson, S.A.K. (1912). Progressive lenticular degeneration: a familial nervous disease associated with cirrhosis of the liver. Brain, 34, 295-508.

Yamaguchi, Y., Heiny, M.E., \& Gitlin, J.D. (1993). Isolation and characterization of a human liver cDNA as a candidate gene for Wilson disease. Biochemistry Biophysics and Research Communication, 197, 271-277.

Table 1. Serum ceruloplasmin levels and Urinary copper level of WND patients (p1-p11). The patients were presented with hepatic, neurological or with both complications

\begin{tabular}{|l|l|l|}
\hline Patients & $\begin{array}{l}\text { Ceruloplasmin } \\
(\mathrm{mg} / \mathrm{dl})\end{array}$ & Urinary Copper ug/24hrs \\
\hline $\mathrm{p} 1$ & 15 & 1200 \\
\hline $\mathrm{p} 2$ & 10 & 1800 \\
\hline $\mathrm{p} 3$ & 12 & 700 \\
\hline $\mathrm{p} 4$ & 9.7 & 800 \\
\hline $\mathrm{p} 5$ & 18 & 2000 \\
\hline $\mathrm{p} 6$ & 16 & 1800 \\
\hline $\mathrm{p} 7$ & 20 & 2100 \\
\hline $\mathrm{p} 8$ & 6.8 & 1796 \\
\hline $\mathrm{p} 9$ & 15 & 1600 \\
\hline p10 & 20 & 1000 \\
\hline p11 & 20 & 500 \\
\hline Controls (30) & $35($ average $)$ & $80($ average $)$ \\
\hline Normal & $<20 \mathrm{mg} / \mathrm{dl} *$ & $>100 \mu \mathrm{g} / 24 \mathrm{~h} *$ \\
\hline
\end{tabular}

*(Sternlieb 1990) 
Table 2. Hematological Analysis in Wilson disease patients

\begin{tabular}{|c|c|c|c|c|c|c|}
\hline Patients & $\mathrm{Hb}$ & Total Bilirubin & AST & ALT & ALP & Serum Albumin \\
\hline $\mathrm{P} 1$ & $7.9 \mathrm{~g} / \mathrm{dl}$ & $4.4 \mathrm{mg} / \mathrm{dl}$ & $215 \mathrm{U} / \mathrm{L}$ & $30 \mathrm{U} / \mathrm{L}$ & $304 \mathrm{U} / \mathrm{L}$ & $2.4 \mathrm{~g} / \mathrm{dl}$ \\
\hline $\mathrm{P} 2$ & $10.5 \mathrm{~g} / \mathrm{dl}$ & $4.5 \mathrm{mg} / \mathrm{dl}$ & $160 \mathrm{U} / \mathrm{L}$ & $91 \mathrm{U} / \mathrm{L}$ & $2264 \mathrm{U} / \mathrm{L}$ & $2 \mathrm{~g} / \mathrm{dl}$ \\
\hline P3 & $8.7 \mathrm{~g} / \mathrm{dl}$ & $30 \mathrm{mg} / \mathrm{dl}$ & $200 \mathrm{U} / \mathrm{L}$ & $40 \mathrm{U} / \mathrm{L}$ & $350 \mathrm{U} / \mathrm{L}$ & $1.7 \mathrm{~g} / \mathrm{dl}$ \\
\hline P4 & $6.7 \mathrm{~g} / \mathrm{dl}$ & $26.8 \mathrm{mg} / \mathrm{dl}$ & $945 \mathrm{U} / \mathrm{L}$ & $160 \mathrm{U} / \mathrm{L}$ & $150 \mathrm{U} / \mathrm{L}$ & $2 \mathrm{~g} / \mathrm{dl}$ \\
\hline P5 & $5.5 \mathrm{~g} / \mathrm{dl}$ & $26 \mathrm{mg} / \mathrm{dl}$ & $200 \mathrm{U} / \mathrm{L}$ & $100 \mathrm{U} / \mathrm{L}$ & $300 \mathrm{U} / \mathrm{L}$ & $2.3 \mathrm{~g} / \mathrm{dl}$ \\
\hline P6 & $10.5 \mathrm{~g} / \mathrm{dl}$ & $2 \mathrm{mg} / \mathrm{dl}$ & $40 \mathrm{U} / \mathrm{L}$ & $45 \mathrm{U} / \mathrm{L}$ & $95 \mathrm{U} / \mathrm{L}$ & $4.4 \mathrm{~g} / \mathrm{dl}$ \\
\hline P7 & $4.5 \mathrm{~g} / \mathrm{dl}$ & $1.9 \mathrm{mg} / \mathrm{dl}$ & $215 \mathrm{U} / \mathrm{L}$ & $20 \mathrm{U} / \mathrm{L}$ & $300 \mathrm{U} / \mathrm{L}$ & $2 \mathrm{~g} / \mathrm{dl}$ \\
\hline P8 & $8.9 \mathrm{~g} / \mathrm{dl}$ & $1.8 \mathrm{mg} / \mathrm{dl}$ & $1400 \mathrm{U} / \mathrm{L}$ & $40 \mathrm{U} / \mathrm{L}$ & $569 \mathrm{U} / \mathrm{L}$ & $2.3 \mathrm{~g} / \mathrm{dl}$ \\
\hline P9 & $5.2 \mathrm{~g} / \mathrm{dl}$ & $2.9 \mathrm{mg} / \mathrm{dl}$ & $50 \mathrm{U} / \mathrm{L}$ & $122 \mathrm{U} / \mathrm{L}$ & $272 \mathrm{U} / \mathrm{L}$ & $2.2 \mathrm{~g} / \mathrm{dl}$ \\
\hline P10 & $5 \mathrm{~g} / \mathrm{dl}$ & $30 \mathrm{mg} / \mathrm{dl}$ & $450 \mathrm{U} / \mathrm{L}$ & $200 \mathrm{U} / \mathrm{L}$ & $350 \mathrm{U} / \mathrm{L}$ & $2.2 \mathrm{~g} / \mathrm{dl}$ \\
\hline P11 & $\begin{array}{l}10.2 \\
\mathrm{~g} / \mathrm{dl}\end{array}$ & $2.4 \mathrm{mg} / \mathrm{dl}$ & $85 \mathrm{U} / \mathrm{L}$ & $85 \mathrm{U} / \mathrm{L}$ & $312 \mathrm{U} / \mathrm{L}$ & $2.5 \mathrm{~g} / \mathrm{dl}$ \\
\hline Normal & $\begin{array}{l}\text { 13-17 } \\
\text { g/dl }\end{array}$ & $0.3-1.2 \mathrm{mg} / \mathrm{dl}$ & $7-45 \mathrm{U} / \mathrm{L}$ & $7-45 \mathrm{U} / \mathrm{L}$ & 98-279 U/L & $3.5-5.5 \mathrm{~g} / \mathrm{dl}$ \\
\hline
\end{tabular}

Note. Hb, hemoglobin; AST, aspartate aminotransferase; ALT, alanine, aminotransferase; ALP, alkaline phosphatase; 


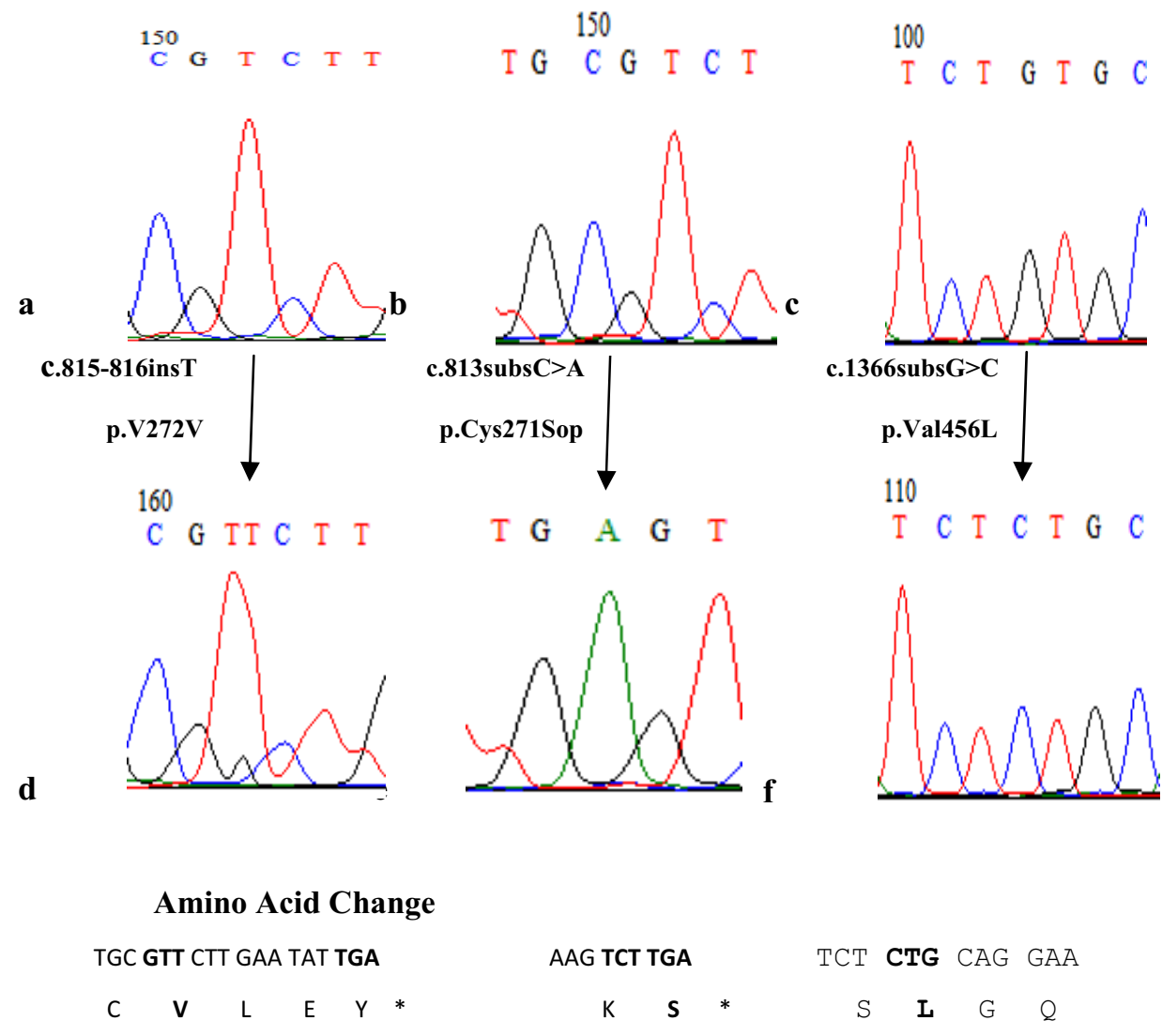

Figure 1. a-c: The DNA sequence of controls. d-f, The DNA sequence of the patients shows a insertion of $\mathrm{T}$, substitution of $\mathrm{C}>\mathrm{A}, \mathbf{G}>\mathbf{C}$ (as indicated by an arrow). The DNA sequencing of patients and controls was performed with forward and reverse primers for the confirmation of sequence change. 